\title{
Distomatosis hepática en bovinos y zoonosis. Factores de riesgos para la salud pública
}

\author{
Hepatic dystomatosis in cattle and zoonoses. Risk factors for public health \\ Distomatose hepática em bovinos e zoonoses. Fatores de risco para saúde pública
}

Cristina Bejarano Rivera

ci.bejarano@uta.edu.ec

https://orcid.org/0000-0001-7052-5396

Universidad Técnica de Ambato, Ambato-Ecuador

\section{Alonzo Chicaiza Sánchez}

luis.chicaiza@utc.edu.ec

https://orcid.org/0000-0002-8639-7891

Universidad Técnica de Cotopaxi, Latacunga-Ecuador

\author{
Rafael Garzón Jarrín \\ rafael.garzon@utc.edu.ec \\ https://orcid.org/0000-0001-9055-3079
}

Universidad Técnica de Cotopaxi, Latacunga-Ecuador

\author{
Rafael Mera Andrade \\ ri.mera@uta.edu.ec \\ https://orcid.org/0000-0002-6996-2764
}

Universidad Técnica de Ambato, Ambato-Ecuador

Artículo recibido 10 de agosto 2021 / Arbitrado y aceptado 9 de septiembre 2021 / Publicado 13 de diciembre 2021

\section{RESUMEN}

La Distomatosis hepática también conocida como Fascioliasis es una enfermedad parasitaria de los animales herbívoros, de manera especial de la especie bovina y zoonótica. Por lo tanto, se planteó recopilar información de literatura sobre Distomatosis hepática o fascioliasis en bovinos, zoonosis y factores de riesgo e interés sobre la salud pública, de igual manera analizar el número de casos mediante un estudio retrospectivo sobre la prevalencia de hígados decomisados por la presencia del parásito Fasciola hepática en el Camal Municipal de Ambato entre los años 2019, 2020, 2021 (primer semestre). La metodología que se utilizó fue exploratoria y descriptiva a través de revisión bibliográfica de artículos científicos publicados en diferentes bases de datos publicados por varios autores que permite obtener información de la Distomatosis o fascioliasis hepática. Se tomó toda la población de reses que llegaron a ser faenadas; en el año 2019 de 21,276, en el 2020 de 12.396 este disminuyó por restricciones de la pandemia COVID-19 y para el 2021(primer semestre) de 6.570 bovinos. Los datos fueron ubicados en tablas de contingencia, se analizó la prevalencia de Distomatosis hepática o fascioliasis, para el año 2019 de 7.96\%, para 2020 de $7.21 \%$ y para el 2021 de $6.49 \%$; con un promedio de los tres años del $7.22 \%$, de esta manera se demuestra la existencia Distomatosis en el Camal Municipal de Ambato-Ecuador; se recomienda un plan sobre el manejo, prevención y control, tratamiento y erradicación de dicho parásito y dar a conocer a la población sobre los factores de riesgo.

Palabras clave: Distomatosis; Bovina; Zoonótica; Retrospectivo; Prevalencia

\section{ABSTRACT}

Hepatic dystomatosis, also known as Fascioliasis, is a parasitic disease of herbivorous animals, especially of the bovine and zoonotic species. Therefore, it was proposed to collect information from the literature on liver dystomatosis or fascioliasis in bovines, zoonoses and risk factors and public health interest, in the same way to analyze the number of cases through a retrospective study on the prevalence of livers seized by the presence of the Fasciola hepatic parasite in the Ambato Municipal Camal between the years 2019, 2020, 2021 (first semester). The methodology that was used was exploratory and descriptive through a bibliographic review of scientific articles published in different databases published by various authors, which allows obtaining information on liver dystomatosis or fascioliasis. The entire population of cattle that came to be slaughtered was taken; In the year 2019 of 21,276, in 2020 of 12,396 this decreased due to restrictions of the COVID-19 pandemic and by 2021 (first semester) of 6,570 cattle. The data were placed in contingency tables, the prevalence of hepatic distomatosis or fascioliasis was analyzed, for the year 2019 of $7.96 \%$, for 2020 of $7.21 \%$ and for 2021 of $6.49 \%$; With an average of the three years of $7.22 \%$, in this way the existence of Distomatosis in the Camal Municipal de Ambato-Ecuador is demonstrated; It is recommended a plan on the management, prevention and control, treatment and eradication of this parasite and make the population aware of the risk factors.

Key words: Dystomatosis; Bovine; Zoonotic; Retrospective; Prevalence

\section{RESUMO}

animais herbívoros, principalmente da espécie bovina e zoonótica. Portanto, propôs-se coletar informações da literatura sobre distomatose ou fascioliose hepática em bovinos, zoonoses e fatores de risco de interesse para a saúde pública, da mesma forma que analisar o número de casos por meio de um estudo retrospectivo sobre a prevalência de fígados apreendidos pela presença do parasita hepático Fasciola no Ambato Municipal Camal entre os anos 2019, 2020, 2021 (primeiro semestre). A metodologia utilizada foi exploratória e descritiva por meio de revisão bibliográfica de artigos científicos publicados em diferentes bases de dados publicadas por diversos autores, o que permite obter informaçōes sobre distomatose hepática ou fasciliose. Toda a população de gado que veio para ser abatido foi levada; no ano de 2019 de 21.276, em 2020 de 12.396 está diminuiu devido às restrições da pandemia COVID-19 e até 2021 (primeiro semestre) de 6.570 bovinos. Os dados foram localizados em tabelas de contingência, analisou-se a prevalência de distomatose ou fascioliose hepática, para o ano de 2019 de 7,96\%, para 2020 de $7,21 \%$ e para 2021 de $6,49 \%$; com uma média dos três anos de 7,22\%, desta forma fica demonstrada a existência de Distomatosis no Camal Municipal de Ambato-Equador; recomenda-se um plano de manejo, prevenção e controle, tratamento e erradicação deste parasita e conscientização da população sobre os fatores de risco.

Palavras-chave: Distomatose; Bovino; Zoonótico; Retrospectivo; Prevalência 


\section{INTRODUCCIÓN}

La Distomatosis hepática o fascioliasis en la especie bovina es una enfermedad parasitaria, de mayor prevalencia en el mundo, para los productores es de interés económico por el decomiso de los hígados infectados con este parásito en los centros de faenamiento; en el ámbito de producción pecuaria genera pérdidas económicas y de interés en el tema de salud pública porque es una enfermedad propia de animales que se transmite hacia el humano (zoonosis) ocasionando lesiones graves sobre el hígado y conductos biliares (1).

Entre los objetivos propuestos para la presente investigación se encuentran: Recopilar información de literatura sobre Distomatosis hepática o fascioliasis en bovinos, zoonosis y factores de riesgo e interés sobre la salud pública. Analizar el número de casos mediante un estudio retrospectivo sobre la prevalencia de hígados decomisados por la presencia del parásito Fasciola hepática en el Camal Municipal de Ambato en los años 2019 , 2020, 2021 (primer semestre). La F. hepática es un parásito que puede contraer el bovino y el humano por la ingesta de aguas contaminadas, consumo del hospedador intermediario que son los caracoles (molusco del género Lymnaea), es una afección que produce una inflamación del hígado y de los conductos biliares, siendo en su mayor frecuencia crónica y de trastornos nutritivos tales como diarreas, pérdida de peso, así mismo se menciona en investigaciones una transmisión transplacentaria $(2,3)$.

La importancia radica en obtener información relevante de datos publicados de varios autores que permitirá un análisis sobre la Distomatosis hepática o fascioliasis y de datos obtenidos en el Camal Municipal de Ambato, se analizará cuál es la prevalencia, esto dará un panorama real sobre la problemática de la enfermedad.

\section{MATERIALES Y MÉTODOS}

El área de estudio estuvo ubicada en la Provincia de Tungurahua, cantón Ambato. Se tomó toda la población de bovinos que llegaron a ser faenados; en los años 2019, 2020 y 2021 (primer semestre), se registró los casos positivos de F. Hepática mediante la valoración diagnostica del examen macroscópico post mortem con la presencia de los parásitos en el hígado. Los datos fueron ubicados en tablas de contingencia, se registró los números de casos positivos de cada mes.

La metodología que se utilizó fue la exploratoria-descriptiva, la primera fase exploratoria, se utilizó para recabar información de publicaciones de autores sobre la Distomatosis hepática o fascioliasis en bovinos, zoonosis, morfología, ciclo biológico del parásito, medios de contagio, signos y síntomas, morbilidad y mortalidad, diagnóstico, medidas de control, prevención y factores de riesgo e interés sobre la salud pública y la segunda fase descriptiva mediante el análisis de prevalencia de F. hepática en el Camal Municipal de Ambato-Ecuador.

\section{RESULTADOS Y DISCUSIÓN}

La metodología que se utilizó fue la exploratoria - descriptiva. Para la primera 
fase exploratoria se recabo información importante como se detalla a continuación: La Distomatosis hepática o fascioliasis es una enfermedad causada por transmisión del parásito F.hepática, puede contraer el bovino y el humano por la ingesta de aguas contaminadas, consumo del hospedador intermediario que son los caracoles (molusco del género Lymnaea), esta afección consiste en una inflamación del hígado y de los conductos biliares, siendo en su mayor frecuencia crónica y ocasiona trastornos nutritivos tales como diarreas, pérdida de peso, así mismo se menciona en investigaciones una transmisión transplacentaria $(2,3)$.

En cuanto a su morfología es un trematodo, tiene cuerpo ensanchado y algo aplanado en su sector dorsoventral, llegan a medir $3 \mathrm{~cm}$ de largo y 1,3 cm de ancho, posee dos ventosas, la ventral es la más grande que la del sector de la boca. Su aparato digestivo y reproductor están bifurcados, tienen dos testículos sobre parte media corporal, un ovario y un útero localizados antes de los testículos, son hermafroditas, en su parte exterior se observa un tegumento recubierto por numerosas espinas dirigidas hacia atrás que le sirven para movilizarse y lesionan los conductos biliares así como el parénquima hepático con su desplazamiento, la Fasciola adulta tiene una forma lanceolada semejante a una hoja de laurel se le conoce también como duela del hígado, internamente se encuentra incompleto su aparato digestivo, conformado por una pequeña cavidad bucal continuando con la faringe y el esófago que llega a bifurcarse en dos ramas laterales, ambas ramas terminan en ciegos intestinales $(1,4)$.

Por otra parte, el ciclo biológico del parásito requiere de las condiciones adecuadas de temperatura y humedad. Por estas situaciones se incrementa la prevalencia en época de lluvia, así como en ambientes húmedos y se reportan casos en temperaturas templadas (3).

En su ciclo biológico atraviesa varias etapas:1. Los huevos anembrionados pasan a la materia fecal por los conductos biliares y salen del organismo. 2. Los huevos son fecundados en el agua. 3. Los huevos liberan miracidias, que ingresan en los caracoles (huésped intermedio). 4. En los caracoles los parásitos atraviesan varios estadios de desarrollo (esporocistos, rediasy cercarias).5. Lascercarias son liberadas por los caracoles y se enquistan como metacercarias en la vegetación acuática u otras superficies. 6. La fascioliasis se adquiere al comer plantas, pasto, especialmente, que contienen metacercarias. 7. Después de su ingestión, las metacercarias salen de sus quistes en el duodeno. 8. Las metacercarias al llegar al intestino se transforman en Fasciolas jóvenes migran a través de la pared intestinal, la cavidad peritoneal (Estadio prehepático) y el parénquima hepático agujeran la cápsula hepática (Estadio hepático), continúan migrando a través del parénquima (Fase parenquimatosa o periodo migratorio) por un tiempo estimado de 6 a 7 semanas hasta arribar a los hacia los conductos biliares (Fase biliar o período biliar crónico), donde se convierten en adultos; con la deposición de huevos después de 8 a 12 semanas de la infección completan 
su ciclo vital, provocando un daño severo en el hígado e intestinos. Empiezan a eliminar huevos a través de las heces del animal afectado $(2,5,6)$.

Como medios de contagio, la fascioliasis se adquiere por la ingestión de plantas acuáticas, berros silvestres, hongos y por agua contaminada por metacercarias, su transmisión es por la vía feca-oral (7).

Los bovinos parasitados no muestran signos dentro de los primeros días, solamente se percibe un poco de somnolencia, decaimiento y debilidad muscular pero conserva su apetito, en el segundo periodo, ya presenta síntomas más claros como el surgimiento de mucosas pálidas, falta de apetito lo cual conlleva anorexia, y sed intensa, pero el factor más importante es el surgimiento de edemas en el pecho, vientre y quijada, posteriormente diarreas lo cual es factor crucial para la deshidratación y posterior muerte del animal. El período de incubación varía de 3 a 8 e incluso 12 semanas, en el transcurso de este período puede ser evidente la aparición de varios animales muertos del rebaño tendidos sobre su pecho, con los ollares apoyados en el suelo como si el ejemplar hubiera fallecido mientras dormía, en varios casos puede ser confundida con un trastorno infeccioso como clostridiasis (2,8-10).

En efecto, su morbilidad y mortalidad, se menciona que es una enfermedad de mayor prevalencia de climas fríos y templados. Como morbilidad en ganaderías de leche: depresión, anorexia, disminución de la producción de láctea, reducción de peso, colangitis, obstrucción biliar, fibrosis hepática hasta calcificación de los conductos biliares y decomisos de hígados en el camal o matadero, así la muerte del animal. (1,11-13).

Para el diagnóstico clínico de la Distomatosis Hepática: Examen parasitológico, se realiza mediante la sedimentación a partir de las heces; el inmunodiagnóstico permite encontrar anticuerpos surgidos del mismo parásito causante de la enfermedad, se introducen las técnicas de ELIZA FhES; y la otra técnica es RAPDs-PCR, su aplicación es en los camales con problemas como hipertrofia o hemorragias en el hígado $(14,15)$.

Otro examen que se realiza de manera directa de tipo macroscópico en los centros de faenamiento son los hallazgos en la necropsia se puede observar laceraciones como fibrosis postnecrótica, fibrosis isquémica (reconstrucción de las áreas de necrosis coagulativa) y micro trombos originados por los trematodos en las sinusoides hepáticas, fibrosis parasitaria bucal, y el hígado se encuentra hipertrofiado y hemorrágico con numerosas fasciolas de 1-7 $\mathrm{mm}$ en el parénquima hepático, peritoneo, páncreas y pulmones $(3,9)$.

Concretamente las medidas de control y prevención para Distomatosis es el tratamiento es el triclabendazol, droga de administración oral en dosis única en un día de $10 \mathrm{mg} / \mathrm{kg}$, o bien $20 \mathrm{mg} / \mathrm{kg}$ en una dosis única o dividida en dos días seguidos acompañada de una comida grasa para mejorar la absorción. La aparición de resistencia al triclabendazol en varias partes del mundo ha hecho que en la 
actualidad se haya ensayado combinar este imidazol con derivados de la artemisina con resultados satisfactorios (16).

Por último, como factor de riesgo e interés sobre la salud pública; para los seres humanos se ve en el consumo de hígado mal cocido que sea proveniente de un animal infectado o enfermo, en los niños afectados se da un desarrollo físico e intelectual lento, por ingerir o masticar plantas que se obtiene en el campo y que no necesariamente son alimento, además el consumir bebidas elaboradas con vegetales locales y beber agua en la que flotan metacercarias (forma larval del parásito) puede ser un factor de riesgo crucial, pero los contagios más frecuentes se presentan al consumir hígados de un animal infectado (6). En la Figura 1 se muestra un hígado con $F$. hepática.

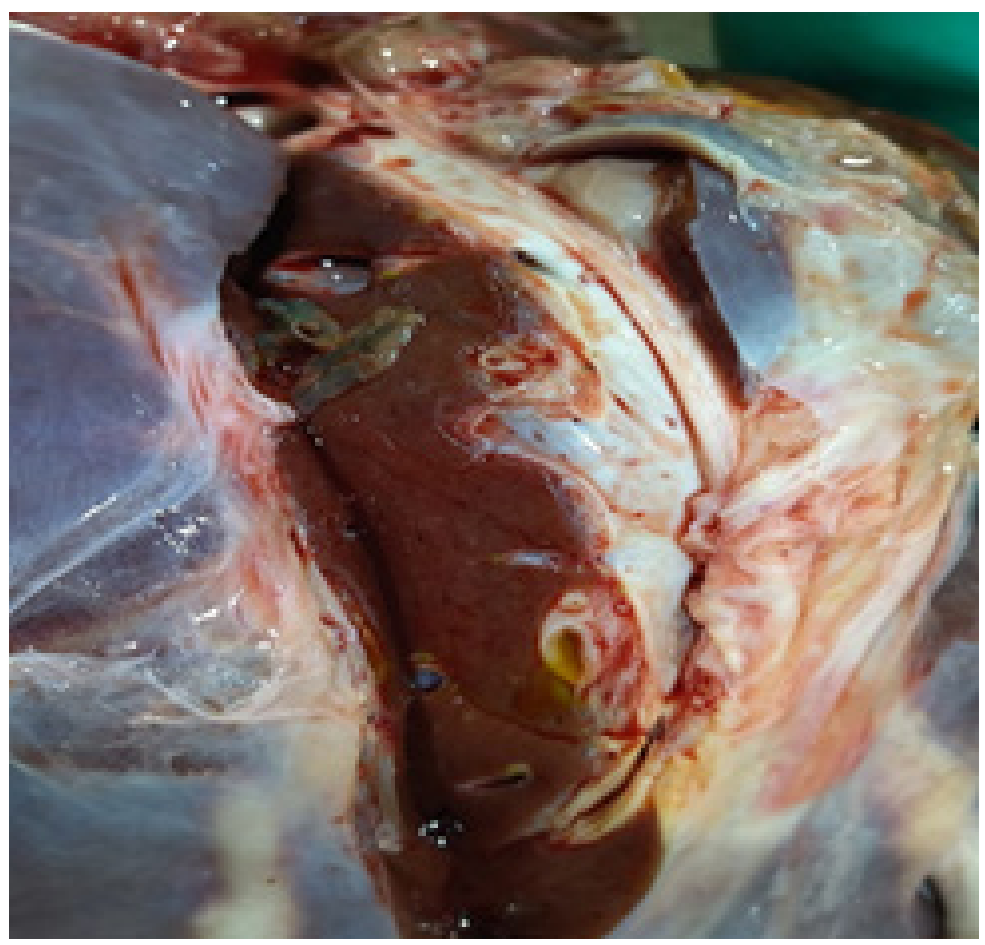

Figura 1. Examen Macroscópico, presencia de Distomatosis o fascioliasis en hígado.

Fuente: Camal Municipal de Ambato.

Figura 1 se aprecia la presencia del parásito de $F$. hepática en un hígado decomisado en el Camal Municipal de Ambato. Mediante el examen macroscópico.

Para la segunda fase descriptiva, se procedió a ubicar los datos en las tablas de contingencia, de acuerdo a los años 2019, 2020, 2021 (primer semestre), registrando el número de hígados decomisados en cada mes en el Camal Municipal de Ambato. 
Tabla 1. Hígados decomisados en el Camal Municipal de Ambato años 2019, 2020, 2021 (primer semestre).

\begin{tabular}{cccc}
\hline MESES & $\mathbf{2 0 1 9}$ & $\mathbf{2 0 2 0}$ & $\mathbf{2 0 2 1}$ \\
\hline ENERO & 165 & 157 & 63 \\
FEBRERO & 119 & 137 & 60 \\
MARZO & 119 & 152 & 110 \\
ABRIL & 104 & 35 & 83 \\
MAYO & 103 & 23 & 76 \\
JUNIO & 178 & 46 & 106 \\
JULIO & 148 & 46 & - \\
AGOSTO & 138 & 57 & - \\
SEPTIEMBRE & 145 & 56 & - \\
OCTUBRE & 170 & 64 & - \\
NOVIEMBRE & 146 & 47 & - \\
DICIEMBRE & 159 & $\mathbf{8 9 4}$ & - \\
\hline TOTAL & $\mathbf{1 . 6 9 4}$ & $\mathbf{4 9 8}$ \\
\hline
\end{tabular}

Fuente: Camal Municipal de Ambato.

En la Tabla 1 se muestra el número de hígados decomisados en el Camal Municipal de Ambato, en el año 2019 se aprecia un total de 1.694, en el 2020 con 894 este disminuyó por las restricciones de acceso al centro de faenamiento por la situación COVID-19 y 2021 (primer semestre) 498 casos. Dejan claro los valores correspondientes a los casos positivos a F. hepática para cada mes.

Tabla 2. Datos de Bovinos Faenados 2019, 2020 y 2021 (primer semestre).

\begin{tabular}{ccccccc}
\hline DATOS: & $\mathbf{2 0 1 9}$ & Porcentaje & $\mathbf{2 0 2 0}$ & Porcentaje & $\mathbf{2 0 2 1}$ & Porcentaje \\
\hline TOTAL, RESES FAENADAS ANUAL & 21.276 & $100 \%$ & 12.396 & $100 \%$ & 6.570 & $100 \%$ \\
\hline
\end{tabular}

Fuente: Camal Municipal de Ambato.

En la Tabla 2 describe datos de bovinos faenados en el Camal Municipal de Ambato con un total de 21.276 para el año 2019 y 12.396 para el 2020 se aprecia una disminución de reses que llegaron a ser faenadas por las restricciones del COVID-19 y de 6.570 para el 2021 (primer semestre).

Para obtener la prevalencia sobre los datos retrospectivos para cada año, se procedió a analizar los datos mediante la siguiente fórmula: Prevalencia=número de casos/ población total x100. En la Tabla 3. Se muestra la prevalencia de F. hepática para cada año y el total de los tres años de estudio en el Camal Municipal de Ambato. 
Tabla 3. Prevalencia de Distomatosis hepática en Bovinos Faenados 2019, 2020 y 2021 (primer semestre).

\begin{tabular}{|c|c|c|c|c|c|c|c|}
\hline & 2019 & Prevalencia & 2020 & Prevalencia & 2021 & Prevalencia & $\begin{array}{c}\text { TOTAL } \\
\text { Prevalencia } \\
\text { en los } 3 \\
\text { años }\end{array}$ \\
\hline $\begin{array}{c}\text { POSITIVOS DISTOMATOSIS } \\
\text { ANUAL }\end{array}$ & 1.694 & $7.96 \%$ & 894 & $7.21 \%$ & 498 & $6.49 \%$ & $7,22 \%$ \\
\hline
\end{tabular}

Fuente: Camal Municipal de Ambato.

En la Tabla 3 se obtuvo la prevalencia para cada año; para el 2019 de 7.96\%, 2020 de $7.21 \%$ y para el 2021 (primer semestre) de $6.49 \%$. Prevalencia en los tres años es $7,22 \%$.

\section{Discusión}

La prevalencia de Distomatosis hepática o fascioliasis en bovinos faenados en el Camal Municipal de Ambato en Ecuador fue de los años 2019, 2020 y 2021 (primer semestre) fue de $7,22 \%$ datos que llegan a coincidir en la presentación de la enfermedad en otros sectores del país, con un estudio realizado entre los años 2013 y 2018 en Ecuador; se realizaron controles en los distintos mataderos de toda la región interandina, desde el norte, la provincia de Carchi hasta Loja, este parásito requiere de un hábitat húmedo, en las épocas secas presentan una disminución de contagios en los bovinos, llegando así del 10 al 50\% de bovinos en las fincas, entre el periodo del 2013 hasta el 2018, se decomisaron y analizaron 20.625 órganos de los bovinos en los centros de faenamiento como en Ibarra, Otavalo, Antonio Ante y Pimampiro, los resultados muestran un crecimiento lineal de la fascioliasis hepática, adicionalmente en el 2013 existió una prevalencia de $4.37 \%$ de fascioliasis hepática en los bovinos, presentando un crecimiento el $9.28 \%$ en el $2018(16,17)$.

En todo el mundo, anualmente los animales rumiantes infectados por este parásito supera los 600.000 .000 de animales, trayendo consigo grandes pérdidas económicas que son aproximadamente de 200 millones de dólares (17).

Como factor de riesgo para la Salud Pública la Organización Mundial de la Salud (2017), menciona que las enfermedades de origen parasitario son la principal causa de morbilidad se estiman las situaciones de pobreza, deficiencia de higiene personal, consumo de alimentos crudos, escasez de agua potable en América Central y Sudamérica las afecciones parasitarias son del 45\% (1).

La fascioliasis hepática bovina es considerada como una zoonosis emergente debido al gran impacto que tiene en la salud pública afectando en gran cantidad a poblaciones rurales que se dedican a la agricultura, en Ecuador según estudios del Ministerio de Salud Pública se ha identificado 
que al menos el $1 \%$ de la población humana que vive en las zonas andinas está infectada por este parásito, con una alta morbilidad en estos territorios y se reporta en camales decomisos de hígados con Distomatosis del 10 al $50 \%$ en fincas ganaderas (18).

Se la considera como una enfermedad parasitaria grave en el ser humano, viéndose en mayor cantidad en territorios donde el consumo de alimentos y verduras no cuentan con una higiene adecuada consumiendo verduras crudas, en plantas como la lechuga y alfalfa, también se transmite por el consumo de agua no procesada ni purificada proveniente está de manantiales. Otro factor de riesgo se ve marcado en el consumo de hígado mal cocido que sea proveniente de un animal infectado o enfermo, se afirma que las personas más susceptibles a este parásito son los niños a quienes los afecta creando un desarrollo físico e intelectual lento o bien por ingerir o masticar plantas que se obtiene en el campo y que no necesariamente son alimento, además el consumir bebidas elaboradas con vegetales locales y beber agua en la que flotan metacercarias (forma larval del parásito) puede ser un factor de riesgo crucial, pero los contagios más frecuentes se presentan al consumir productos de un animal infestado como vísceras contaminadas $(6,19)$.

Para prevenir la zoonosis es necesario emplear diferentes mecanismos, informando a la comunidad el riesgo que corre toda la población al no mantener una higiene adecuada con los alimentos de consumo diario, tratando en lo posible que estas zonas rurales cuenten con los servicios básicos de agua potable y no se vean en la necesidad de recurrir a la ingesta de agua no purificada, tener un control de plagas continuó, conservando el alimento del ganado en óptimas condiciones para su consumo (14).

Cuando los animales ingresan al matadero un Médico Veterinario debe analizar todas las vísceras del animal inspeccionando que no haya presencia de este parásito, teniendo un control riguroso para evitar la venta de hígado contaminado y que este no afecte a la salud pública (19).

Este parásito puede ocasionar afecciones tanto en animales y a su vez puede contraer el hombre (zoonosis) por lo tanto de interés en la salud pública tiene su origen en agentes patógenos entre las especies animales y mediante el consumo de sus derivados; el ciclo involucra a dos hospedadores como causantes de la enfermedad, un hospedador intermediario que es el caracol de agua dulce quien aloja a las metacercarias y el agua debido a que la F. hepática tiene la capacidad para mezclarse con las moléculas de agua en arroyos y lagunas atacando de manera directa al animal y a su vez al hombre (20).

\section{CONCLUSIONES}

Se puede concluir según los datos arrojados basados en los objetivos planteados, se logró recabar información relevante en lo que respecta a la Distomatosis hepática o Fascioliasis sobre morfología, ciclo biológico, vías de transmisión, zoonosis, signos y síntomas 
que se presenta en los bovinos, diagnóstico y tratamiento; además incluir los factores de riesgo para la salud pública, en definitiva se realizó un análisis retrospectivo de prevalencia de los años 2019, 2020, y 2021(primer semestre) donde se establece un $7.22 \%$ de prevalencia de hígados decomisados en el Camal Municipal de Ambato que en conclusión nos da un panorama de la realidad de las Fascioliasis en bovinos y si existe la presencia del parásito F. hepática en los hígados; esto nos lleva a realizar una análisis de la situación sobre el manejo, prevención, control ,tratamiento y erradicación de dicho parásito, ya que si no se mantiene una estricta vigilancia epidemiológica estas vísceras pueden llegar a ser consumidas por los humanos y ocasionar problemas en la salud, convirtiéndose en una zoonosis. Un análisis más profundo sobre la situación económica nos permite discutir que pueden existir camales clandestinos donde no se lleva un estricto procedimiento e inspección de las vísceras; y algunos productores pueden evadir está situación al no acudir a un camal certificado por el motivo de pérdidas económicas y por lo tanto siendo una bomba en la propagación de enfermedades parasitarias de tipo zoonótico.

Para terminar, esta enfermedad en los humanos puede ocasionar malestar estomacal, hepatomegalia, náuseas, vómitos, elevación en la temperatura, urticaria, eosinofilia, molestias generales y descenso gradual de la masa corporal lo cual es consecuencia directa de la lesión del hígado, mientras que, la infección grave puede ser asintomática u ocasionar dolor abdominal intermitente, colelitiasis, colangitis esclerosante, ictericia por obstrucción o pancreatitis, y cirrosis biliar, sumado a lo anterior, es posible observar lesiones en la pared intestinal, pulmones $u$ otros órganos, por otra parte, también se han encontrado casos de fascioliasis faríngea que producen disfagia posterior a la ingesta de hígado sin una preparación observado en un estudio en el Medio Oriente donde se tiene el hábito de consumir vísceras crudas o a medio coser (7).

\section{REFERENCIAS BIBLIOGRÁFICAS}

1. Fuentes M, Díaz A, Pulido M, Bulla DB. Fasciolosis: Una enfermedad emergente. Pensamiento y Acción. Tunja. [Internet] 2018; [citado 202130 julio] 55-56 [aproximadamente 2pp] Disponible en: https://revistas.uptc.edu. co/index.php/pensamiento_accion/article/ view/8623

2. Carrada H, Bravo T. Fasciola Hepática: Ciclo Biológico y potencial biótico. Latinoamericana de Patología Clínica y Medicina de Laboratorio. [Internet] 2007. [citado 202115 junio] 27-27 [aproximadamente 5pp] Disponible en:

https://www.medigraphic.com/pdfs/patol/pt2007/pt071f.pdf

3. Quiroz H, Figueroa J, Ibarra F, López M. Epidemiología de Enfermedades Parasitarias en Animales Domésticos. Primera ed. México DF: FMVZ-UNAM. Internet] 2011; [citado 202115 junio] 137-173 [aproximadamente 10pp] 1 (1) Disponible en: http://www.untumbes.edu.pe/vcs/ biblioteca/document/varioslibros/0684.\%20 E p id e m i o log \% C 3\% A D a \% 20 de \% 20 enfermedades $\% 20$ parasitarias $\% 20$ en $\% 20$ animales.pdf 
4. Ticona D, Chávez V, Casas V, Chavera C, Li E. Olga. Prevalencia de Fasciola Hepática en Bovinos y Ovinos de Vilcashuamán, Ayacucho. Revista de Investigaciones Veterinarias del Perú. [Internet] 2010; [citado 202118 junio] 21(2) [aproximadamente 5pp] Disponible en: https:// www.redalyc.org/pdf/3718/371838853004.pdf

5. Pearson R. Fascioliasis [Internet] 2020. [citado 202116 junio] 7 [aproximadamente 3pp] Disponible en: https://www.msdmanuals.com/ es/professional/enfermedades-infecciosas/ trematodos-duelas/fascioliasis

6. Sanabria. Enfermedades Parasitarias de los ovinos y otros rumiantes menores en el cono sur de América, INTA. [Internet] 2001; [citado 202120 junio] 1(1) [aproximadamente 15pp] Disponible en: https://inta.gob.ar/sites/default/ files/script-tmp-publi70_-_ver_editores_y_ autores_colaboradores.pdf

7. Centers for Disease Control and Prevention. [Internet] 2019. [citado 202116 junio] 10 [aproximadamente 5pp] Disponible en: https:// www.cdc.gov/dpdx/fascioliasis/index.html

8. Espino $A$, Borges $A$, Duménigo $B$. Coproantígenos de Fasciola Hepática de posible utilidad en el diagnóstico de la fascioliasis. Panamericana de Salud Pública/ Pan American Journal of Public Health. [Internet] 2000 [citado 202110 junio] 7(4) [aproximadamente 8pp] Disponible en: https:// www.scielosp.org/pdf/rpsp/2000.v7n4/225231

9. Covarrubias CMC. Ganaderia.com. [Internet].; 2020. [citado 202105 junio] 655(1) [aproximadamente 5pp]. Disponible en:

https://www.ganaderia.com/destacado/ Fasciolosis-Hep\%C3\%Altica-Bovinos

10. Jeannette D. Zoonosis. Revista Chilena de Infectología. [Internet] 2003. [citado 202114 junio] 20 [aproximadamente 5pp] Disponible en: https://www.scielo.cl/pdf/rci/v20s1/art08. pdf

11. Pruss A, Corvalán C. Organización Mundial de la Salud. [Internet] 2006. [citado
202117 junio] 104 [aproximadamente 2pp] Disponible en: https:// https://apps.who.int/ iris/handle/10665/43452

12. Yagui A, Vidal $M$. Carga de enfermedad en el Perú estimación de loa años saludables 2012. [Internet] 2014. [citado 202117 junio] 86(1) [aproximadamente 5pp] Disponible en: http://www.dge.gob.pe/portal/docs/tools/ Cargaenfermedad2012.pdf

13. Juncosa S, Bolívar B. Medir la morbilidad en Atención Primaria. Reflexiones en medicina de familia. [Internet] 2013. [citado 202118 junio] 6(1) [aproximadamente 5pp] Disponible en: http://www.scielo.org.pe/pdf/amp/v30n1/ a08v30n1.pdf

14. Rodríguez R, Torrado L, Báez R, Santana T. Infestación Humana por Fasciola hepática. Revista Archivo Médico de Camagüey. [Internet] 2002. [citado $2021 \quad 19$ junio] 9 [aproximadamente 5pp] Disponible en: http:// scielo.sld.cu/pdf/amc/v6n6/amc03602.pdf

15. Martínez R, Doménech C, Millan. Fascioliasis, Revisión Clínico-Epidemiológica y Diagnóstico. Rev Cubana Hig Epidemiol. [Internet] 2012. [citado 202120 junio] 50(1) [aproximadamente 5pp] Disponible en:

h t t p s : / / w w w. re da l y c.org / pdf/2232/223230244011.pdf

16. Pacheco $S$. Prevalencia y fatores de riesgo. Fasciola Hepática en bovinos. [Internet] 2017. [citado 202120 junio] 1(1) [aproximadamente 15pp] Disponible en: https://dspace.ups. edu.ec/bitstream/123456789/14556/1/UPSCT007154.pdf

17. Rojas D, Cartín J. Prevalencia de Fasciola hepática y pérdidas económicas asociadas al decomiso de hígados en tres mataderos de clase A de Costa Rica. Agronomía Costarricense. [Internet] 2016 [citado 202126 junio] 40(2) [aproximadamente 5pp] Disponible en: https:// www.scielo.sa.cr/pdf/ac/v40n2/0377-9424ac-40-02-00053.pdf

18. Delgado N, Garcias C. Fasciolosis, zoonosis emergente $\mathrm{y}$ reemergente vista desde una 
dimensión ambiental. VITAE. [Internet] 2013 [citado 202124 junio] 10(1) [aproximadamente 5pp] Disponible en: https://vitae.ucv.ve/pdfs/ VITAE_4870.pdf

19. Valderrama A. Prevalencia de fascioliasis en animales poligástricos de Perú, 1985-2015. Rev Med. [Internet] 2016 [citado 202120 junio] 32(1) [aproximadamente 8pp] Disponible en: ht t p://w w w. scielo.org. c o/scielo.php? script=s ci arttext\&pid=S0122-93542016000200012

20. Moutou F. Nueva Sociedad. Las zoonosis, entre humanos y animales. [Internet] 2020 [citado 202102 junio] 1(1) [aproximadamente 13pp] Disponible en: https://nuso.org/articulo/ las-zoonosis-entre-humanos-y-animales/ 